\title{
Application of micro-course video in optical manufacturing technology
}

Shanshan Wang, Qun Hao, Yifan Huang, Yao Hu, Qianqian Wang, et al.

Shanshan Wang, Qun Hao, Yifan Huang, Yao Hu, Qianqian Wang, Ya Zhou, Mei Hui, Yong Song, "Application of micro-course video in optical manufacturing technology," Proc. SPIE 11143, Fifteenth Conference on Education and Training in Optics and Photonics: ETOP 2019, 111433I (2 July 2019); doi: 10.1117/12.2523766

SPIE Event: Fifteenth Conference on Education and Training in Optics and Photonics: ETOP 2019, 2019, Quebec City, Quebec, Canada 


\title{
Application of micro-course video in optical manufacturing technology
}

\author{
Shanshan Wang, Qun Hao*, Yifan Huang, Yao Hu, Qianqian Wang, Ya Zhou, Mei Hui, Yong Song \\ Beijing Key Lab. for Precision Optoelectronic Measurement Instrument and Technology, \\ School of Optics and Photonics, Beijing Institute of Technology, Beijing 100081, China
}

\begin{abstract}
Optical Manufacturing Technology is a compulsory course for postgraduate and advanced undergraduate majors in optical engineering and similar majors. Modern fabrication and testing equipment are extremely expensive, which cost millions or even tens of millions, and having high requirements for the use environment. Most schools that do not focus on optical fabrication rarely purchase these devices for educational purposes only. Relevant professional teachers are also not familiar with the working principle and use process of the new fabrication and testing equipment such as Computer Controlled Optical Surfacing (CCOS), Magnetorheological Finishing (MRF), Ion Beam Figuring (IBF), laser tracker and LuphoScan interferometer. This has caused the teaching content of the course to stay at the stage of singleaxis machining, knife-edge tester, so that students' knowledge of modern equipment is almost blank. While teaching with micro-course videos, the relevant equipment use process can be visually presented to students, and relevant technical experts can also explain the working principle and scope of application to students more professionally. According to the survey, $82 \%$ of students like this micro-course video teaching, acknowledging that it helps to better understanding modern optical fabrication and testing equipment, expand students' knowledge, and increase students' advantages in employment competition.
\end{abstract}

Keywords: Micro-course video teaching, modern fabrication and testing, optical manufacturing technology

\section{INTRODUCTION}

With the development the rise of advanced equipment, optical manufacturing technology requirements are becoming higher and constantly breaking through the limit. Optical fabrication is no longer simply the two processes of grinding, polishing. However, the optical system in the scientific research and production largely relies on the form of external processing, installation and adjustment. It makes more difficult for students to have a comprehensive understanding of optical manufacturing technology. In this paper, we propose a trial of using micro-course video for the teaching and communication in a senior grade Optical Manufacturing Technology Course (OMTC).

\section{INTRODUCTION TO OPTICAL MANUFACTURING TECHNOLOGY COURSE}

\subsection{Course objective}

OMTC, 16 class hours, is a professional basic course for the junior students in School of Optics and Photonics, Beijing Institute of Technology. OMTC build the perceptual knowledge framework on processing, testing, installing and adjusting technology in optical manufacturing for undergraduate students. And it is highly practical, rich in content, and updated rapidly with the development of instruments and equipment. Through the study of OMTC, students can form a comprehensive understanding of modern optical manufacturing system and advanced manufacturing technology, which may broaden the horizon of undergraduates majoring in optical information science and technology, measurement and fabrication technology and instruments [1-4].

\subsection{Course content}

OMTC is conducted by relying on the optical workshop of the college, and it is mainly guided by experienced technicians, including the following practical contents:

1. Grinding and polishing technology of optical plane;

2. Grinding and polishing technology of optical sphere;

3. Surface quality measurement technology using Newton interferometer.

Fifteenth Conference on Education and Training in Optics and Photonics: ETOP 2019, edited by

Anne-Sophie Poulin-Girard, Joseph A. Shaw, Proc. of SPIE Vol. 11143, 111433I · c) 2019

SPIE, ICO, IEEE, OSA · CCC code: 0277-786X/19/\$18 · doi: 10.1117/12.2523766

Proc. of SPIE Vol. 11143 111433I-1 
In the famous international optical college, for example, the College of Optical Sciences at the University of Arizona, OMTC enables the undergraduates to learn about the processes of fabrication, testing, and alignment technology from the most traditional to the most advanced by allowing students to practical operate, or observe. Optical fabrication includes the original two-plane hand grinding, the traditional grinding machine, polishing machine, watching the most advanced stress plate polishing, Computer Controlled Optical Surfacing, Magnetorheological Finishing and Ion Beam Figuring technology. Optical measurement includes the knife-edge test, Hartmann test, Newton interferometer, ShackHartmann wave-front sensing technology, the commercial laser digital interferometer, anti-vibration interferometer and the CGH compensator. Optical alignment equipment includes laser tracker, auto-collimator, self-collimating microscope (PSM) and three-coordinate measuring machine.

Over the years, the traditional optical institute in China, for example, School of Optoelectronic Engineering in Changchun University of Science and Technology, has been insisting on systematically teaching and practicing the course of Optical Technology. They also purchased the distance learning class of the College of Optical Sciences in University of Arizona. Also, under the closely cooperation of Changchun Institute of Optics, Fine Mechanics and Physics, Chinese Academy of Sciences, they organized students to visit and learn the new generation optical manufacturing technology.

Students' horizon determines their ways of thinking. The more optical manufacturing methods they know, the more reasonable optical system structure and processing methods they can choose. Engineers who understand not only advanced technology but also conventional processing level and process cost are high-tech talents today.

\subsection{Feature and problem of OMTC}

At present, the main problems of OMTC focus on two aspects:

1. The course content is not systematic. Twenty or thirty years ago, optical manufacturing techniques were relatively simple and laborious, and it is concentrated on grinding and polishing. Nowadays, optical manufacturing technology is demanding for a higher standard. The processing of 4-meter off-axis aspheric mirror has become an independent science. The need for ultra-smooth surfaces in ultra-violet and X-ray systems has led to completely different Ion Beam Figuring, Magnetorheological Finishing and other new polishing processes. In order to overcome the change of force, heat and other environmental factors, the system setting and adjustment need real-time detection and real-time correction for 193nm lithography machine. Modern optical manufacturing technology is a systematic manufacturing technology, which is a combination of many high and new technologies, such as physical and chemical properties test, single point diamond turning, laser processing or milling shaping technology, a variety of polishing process, anti-vibration surface shape measurement, micron-grade in-situ test, computer assisted technology, wave aberration real-time measurement and control technology. It is so difficult for skilled workers with rich experience in traditional processing to grasp the development status of optical manufacturing technology comprehensively that they could not present OMTC to students in a rich way.

2. The course content is monotonous, and its capacity is small. At present, the teaching method of OMTC is a single hands-on practice mode in the optical workshop, which can be beneficial to enhance students' perceptual knowledge of optical processing and improve their hands-on ability. However, the single teaching method, coupled with the lack of relevant equipment, results in a monotonous course content and small capacity. Through the study of this course, it is difficult for students to fully grasp the development process and the frontier of optical manufacturing technology.

\section{APPLICATION OF MICRO-COURSE VIDEO TEACHING}

Teachers, engaged in the field of optical manufacturing technology and scientific research, need to join the reform of OMTC. It is necessary for them to collect the historical technology, conventional technology and modern technology in various fields to present a systematic and comprehensive optical manufacturing and measuring status to students. This is for training optical students to broaden their view and lay a solid technical foundation. Teachers should enrich the class forms from a single hands-on operation to a set of operations, demonstration experiments and the deep integration of information technology and teaching content of mooc, micro-class and flipped class operation technology.

\subsection{Development of optical component processing technology}

We set up a sphere experiment of hand polishing to encourage students to understand the material removal mechanism and have a perceptual understanding of the removal efficiency. We also set up micro-course video teaching about optical 
element processing technology, mainly displayed and introduced $4 \mathrm{~m} \sim 8 \mathrm{~m}$ aperture mirror fabrication techniques, common optical element fabrication technology, optical polishing process, single point diamond turning technology, hand polishing technology, Ion Beam Figuring technology, Magnetorheological Finishing technology, stress plate polishing technology, etc.

\subsection{Optical component testing technology and its progress}

We set up laser interferometer surface test and white light profiler for surface roughness measurement demonstration experiment. We also set up the discussion classes about optical element test technology, mainly introduced the optical drawings technical requirements and corresponding test methods, surface shape measurement technology of knife edge method, Hartmann test, fringe reflectiong test, three-dimensional machine surface shape parameters testing technology, laser tracker surface shape parameters testing technology, anti-vibration interference measuring technology, nullcompensator for aspherical measurement, CGH null-compensator for free-form surface measurement, etc.

\subsection{Advanced optical mounting and alignment technology}

We set up micro-course video teaching about advanced optical mounting and alignment technology, mainly introduced the lens centering process, automatic centering principle and operation, optical system mounting and alignment under the monitoring of interferometer, computer-aided alignment, etc.

\subsection{Application of laser processing in the fields of industry and medica}

We set up micro-course video teaching about the application of laser processing in the fields of industry and medical, mainly introduced the application of high-power laser cutting technique in automobile industry and the laser in medical field, such as excimer laser in situ keratoplasty (LASIK).

The new course content and teaching method of application of micro-course video teaching have the following innovations: (1) In terms of teaching content, we systematically narrated the history, current situation and development direction of relevant fabrication, testing and alignment technologies in optical manufacturing technology; The application examples of advanced laser processing technology in industrial production and medical field were presented. (2) In terms of teaching method, we adopted the classroom form of integrated application of micro-class and operation technology of flipped classroom under the trend of deep integration of hands-on operation, demonstration experiment and information technology.

\section{FEEDBACK AND DISCUSSION}

After the first trial for a semester, we did an investigation to check the feedback of the students towards the new communication method. The related questions are listed in Table 1.

Table 1. Questionnaire for the micro-course video based teaching and learning

\begin{tabular}{|c|l|l|}
\hline No. & \multicolumn{1}{|c|}{ Question } & \multicolumn{1}{c|}{ Options } \\
\hline 1 & $\begin{array}{l}\text { What is your opinion on } \\
\text { the introduction of video } \\
\text { micro-course? }\end{array}$ & $\begin{array}{l}\text { A. It is very helpful. It should be used earlier! } \\
\text { B. It is helpless and formalism. } \\
\text { C. I do not like it because it will draw my attention and I can't } \\
\text { touch the actual operation! } \\
\text { D. Other, please specify }\end{array}$ \\
\hline 2 & $\begin{array}{l}\text { If you hold positive } \\
\text { opinion on micro-course } \\
\text { video, what is the reason? }\end{array}$ & $\begin{array}{l}\text { A. The micro-course video allows me to see more cutting- } \\
\text { edge optical manufacturing technology. } \\
\text { B. The video micro-course allows me to clearly see the details } \\
\text { of advanced optical processing, and it is helpful. } \\
\text { interesting. } \\
\text { D. Other, please specify }\end{array}$ \\
\hline
\end{tabular}

We distributed 200 questionnaires and received 164 effective feedbacks. The results are plotted in Fig. 1. 

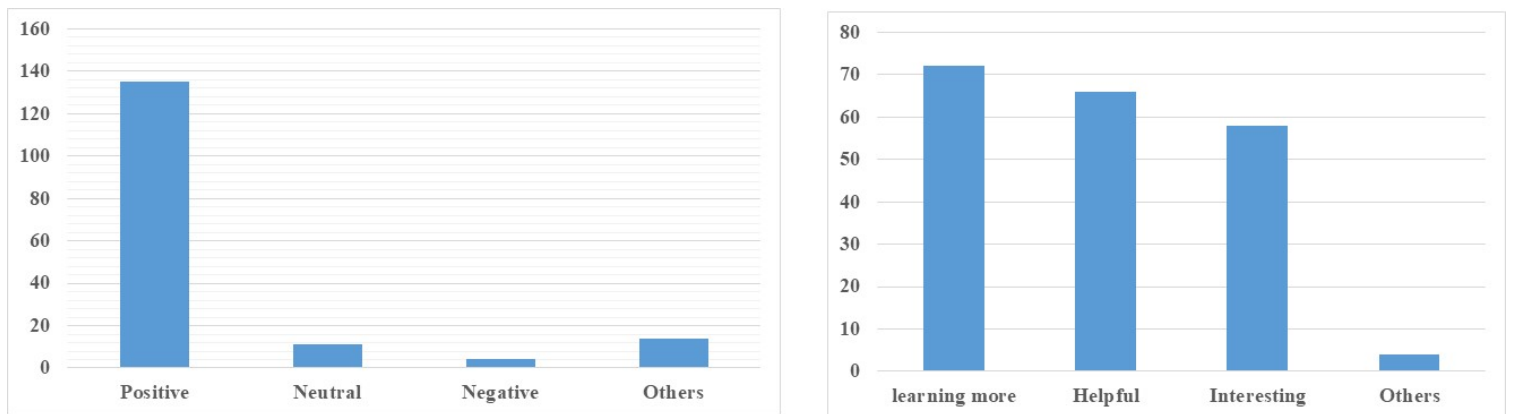

Figure 1. Feedback of the students' attitudes towards the application of micro-course video teaching.

(a) is their attitudes and (b) is the reason for holding positive attitudes.

From Fig. 1(a), we can see that $82 \%$ of the students held positive attitudes to the novel teaching method. Some of the students even expressed that if the application of micro-course video teaching were introduced earlier, he could learn this course much better! That is the best feedback for us. From Fig. 1(b) we know that the trial can help students in understanding the course better. Neutral and Negative attitudes are below $10 \%$. The rest of them raised questions or suggestions in the "Others" option.

\section{CONCLUSION}

In this paper, we introduced our first trial of introducing application of micro-course video teaching into the course of optical manufacturing technology, a comprehensive professional course for senior students. We received instant feedback from students. Investigation showed that $82 \%$ of the students enjoyed this micro-course video teaching, acknowledging that it helps to better understanding modern optical fabrication and testing equipment, expand students' knowledge, and increase students' advantages in employment competition. We still have many problems to be solved and we will figure out new approaches for next trial. We believe that teaching and learning with micro-course video teaching is the development trend and will make more contribute to this area.

\section{REFERENCES}

[1] Ya Zhou, Yao Hu, Liquan Dong, Yuejin Zhao, Yong Song, Qun Hao, “Optoelectronic Instrument Experiments Course: A Trial of Project-based Learning," Proceedings of the 7th International Conference on Computer Science \& Education (ICCSE 2012), Melbourne, Australia, 2012, pp1375-1379.

[2] Susan Ambrose, L. Dee Fink and Daniel Wheeler, "Becoming a Professional Engineering Educator: A New Role for a New Era,” Journal of Engineering Education, Special Issue: The Art \& Science of Engineering Education, 94(1), 2005, pp185-194.

[3] Shavinina L V, Loarer E. "Psychological evaluation of educational multimedia applications," European Psychologist 4(1), 33 (1999).

[4] Boyd R L. Customer Service in Higher Education: Finding a Middle Ground[J]. The Staff Development Forum. Sdf.ac.uk. 